\title{
Challenges and Opportunities for the Future of Media and Mass Communication Theory and Research: Positionality, Integrative Research, and Public Scholarship
}

\author{
Mark Deuze \\ 0000-0002-1986-5050 \\ University of Amsterdam, The Netherlands
}

\begin{abstract}
In this essay I intend to tell a story of media studies and mass communication research as a field, based on the work of the late Denis McQuail - and that of editing the new edition of his seminal handbook McQuail's Media and Mass Communication Theory (McQuail \& Deuze, 2020). Using McQuail's historical storytelling method, I specifically look at the challenge for the field in the context of a global pandemic alongside an infodemic, at a time when the whole world faces the consequences of recurrent lockdowns, social distancing measures, and institutional pressures to stay at home. Media studies and (mass) communication research, while having a distinct narrative, as a field has only just begun to articulate its relevance to society - we have only just started to tell our story. Using developments in understanding the self as a research tool, the implementation of integrative research designs, and calls for engaged and public scholarship, the paper outlines challenges and opportunities for what we can do with our field.
\end{abstract}

KEYWORDS: media studies, mass communication theory, continuity, discontinuity, infodemic.

\section{INTRODUCTION}

The profound role of media and (mass) communication in society and everyday life, once the more or less exclusive domain of academics, has become abundantly clear to everyone in 2020. This heightened awareness is mainly due to a dual convergence happening around the world: the merging of traditional and new media systems into a hybrid media system (Chadwick, 2017), and the confluence of all spheres of life in the 'supra-locale' of the home (Fuchs, 2020). In part, this leaves people wanting more - it is no surprise that visits to public parks and beaches are spiking, that bicycles and garden toys are sold out. Another 
consequence is an accelerated move by institutions and governments to develop and propose all kinds of new policies regarding digital media - including more stringent policies regarding the role (and taxation) of Internet platform companies, the development of new media literacy protocols and curricula, the rapid adoption of information and communication technologies to facilitate distance learning and working from home, and pushing through innovations in the area of telemedicine and digital health applications (Deuze, 2020).

One wonders what the voice of the field of media studies and (mass) communication research in all of this is. At a time when the whole world is wondering (and worried) about media, it seems our field is remarkably absent from public debates. This is not a new situation - throughout our field's history have scholars lamented its absence or silence in the public arena (Waisbord, 2019). Lewis (2020) wonders what communication research is for as it does not seem to participate in the prominent discussions of the day, while Rasmus Kleis Nielsen goes as far to bluntly state that no one cares what we know (2018a). According to Kleis Nielsen (2018 a and b), our field generally lacks real engagement outside the narrow boundaries of academic institutions and audiences, tends not to have a seat at the table where 'elite stakeholder communities' such as journalists, politicians, celebrities, consultants and big business executives set the public agenda, and is often too busy (communicating) with itself than truly caring about others.

Perhaps we can add to this daunting list of woes the significant trouble we have in telling the story of our field - who we are, what we do, why we did it, and what we found. Ours is what Silvio Waisbord calls a 'post-discipline': a permanently impermanent field of study, loosely built on the foundations of many other disciplines while never really coalescing around a more or less consensual paradigm, set of theories, let alone research methods. This despite an impressive number of disciplinary handbooks, textbooks, and canonical readers. The somewhat scattered nature of media and communication research has led to much hand-wringing over the decades, with the field's flagship journal Journal of Communication for example at regular intervals (in 1983, 1993 and 2018) publishing special issues, documenting in detail the on-going fragmentation and specialization of work in the field. We do not seem to have a grand narrative - nothing that connects the many threads that make up media and mass communication teaching and research. We can be a hard sell to the public.

\section{MEDIA AND MASS COMMUNICATION THEORY: A LOOK BACK}

As I am writing this, in late 2020, it makes sense to take a step back to look for the field's overarching story, as it celebrates its first century of scholarship. Where did we come from, how did it start and where has it taken us? 
The argument developed here is taken from earlier work, specifically the 7th edition of McQuail's handbook, warranting a co-authoring credit for the late Denis McQuail. Sections of this paper have been previously published as Deuze (2020 and 2021). Taken together with the current paper, these three publications serve as a trilogy of sorts, aggregating the lessons I have learned from working on McQuail's handbook and applying these to current debates about our field, its role in the pandemic/infodemic, and how it can position itself toward the future in the context of rapid digital transformations in society. Overlap between these works therefore is deliberate, and serves to tie the various arguments together.

The concept of mass communication was first coined during the 1920s or 1930s to apply to the new possibilities for public communication arising from the mass media of the time: press, radio and film. These media enlarged the potential audience beyond a literate minority. The industrial style and scale of the organization of production and dissemination at the time were also essentially new. Large populations could be reached more or less simultaneously with much the same content, often content that carried the stamp of approval of those with political, economic and social power (which were often the same groups of people in many parts of the world).

The context for these developments was one of rapid change in the world of newly industrialized and centralized nation states. It was a time of growth and concentration of population in large cities, of the mechanization and bureaucratization of all aspects of life, and imperialist expansion by the great powers of the time. It was also a period of profound political change, of large social movements, unrest within states, and catastrophic warfare between states. Populations were mobilized towards national achievement or survival and the new mass media played their part in these events as well as providing the masses with the means of relaxation and entertainment. Against this background it is easy to understand why the concept of mass communication was forged and why it rose to a dominant status, pre-occupying the minds of political leaders and business executives alike.

The early meaning of 'mass communication', and one that still lingers, derived much more from the notion of people as a 'mass' and from the perceived characteristics of the mass media than from any idea of communication. The 'mass' was perceived primarily in terms of its size, anonymity, general ignorance, lack of stability and rationality, and as a result was vulnerable to persuasion or suggestion. It was seen to be in need of control and guidance by the superior classes and leaders, and the mass media provided the means for achieving this - by sending messages that people would receive and understand as intended. As 'communication science' developed, a more formal definition of the concept of mass communication emerged that was based on objective characteristics of media 
that could be specified and put to the test. An abstract model of communication was developed with the following typical features:

- A centralized production of content by a few large channels, with a centre-peripheral network of dissemination that was typically hierarchical and one-directional.

- An organization of production and distribution operated according to the logic of the market or as a state-run institution of public communication.

- Message content in standardized forms open to all but also subject to normative and political supervision or control.

- A mass public of receivers made up of many dispersed, anonymous and disconnected individuals.

The attribution of great power to persuade and inform, arising from the prestige or popularity of sources, the monopolistic control of channels, the near instantaneity of reception, the skill of practitioners and the supposedly high impact and appeal of the means employed.

From one perspective, the general hypothesis of mass communication has played a fruitful role by the very fact of being comprehensively disputed and disproved. The research it generated led to a much firmer understanding of key principles underlying mediated communication and our sensemaking thereof. The lessons learned in the process both challenge and confirm the media and mass communication thesis. Overall, early notions of powerful mass media and a more or less one-directional process of mass communication have been waylaid in favour of more nuanced, multidirectional and complex understandings of people and their media, and the role this plays in society.

In today's digital, online and interconnected media environment notions of 'mass' media and 'mass' communication exist side by side with (inter-) personal communication and mass self-communication, and these "three forms of communication coexist, interact, and complement each other rather than substituting for one another" (Castells, 2009: 55). These and other circumstances reflect not the end of mass media or of mass communication, but rather a significant and ongoing shift in the ways that purposes of public communication can be achieved. The early 'industrial' vision of both the ends and means has given way to a different version of mass communication: more personal and private, more targeted and interactive, more diffuse and perhaps even more powerful than before in some instances.

The evolution of a condition or state of mass communication (as redefined), which can now scarcely be distinguished from other social processes (such as individualization, globalization, and urbanization), is primarily due to its high degree of functionality for key driving forces in society and its intimate connection with human aspirations. Many of the actors who benefit from the 
capacity to communicate to all in a measured and calculated way are visible and their motivations are transparent. They include big advertisers and global media firms (both bigger and more concentrated than ever before), the world financial system, rulers and national governments, states with imperial ambitions and concern for their image, international non-governmental organizations, and the list goes on. It is inconceivable that these and others could dispense with the results of even 'smarter' and more effective communication to any chosen public constituency. The emerging, revived and reinforced form of media and mass communication is highly consistent with underlying trends towards convergence and the 'mediation of everything' (Livingstone, 2009). At the same time, the long-term consequences of the new media environment can be expressed in terms that both undermine and reinforce central elements of mass communication theory as developed throughout the 20th century:

- The power of the communicator to persuade or inform selectively is much reduced by the inability to reach large, captive audiences and by the ready availability of alternative sources of ideas and knowledge.

- Individuals are no longer restricted by their immediate social group and environment and by the physical availability of a few media channels, controlled by authorities and other agencies. They can enter and belong to new groups and communities across time and space.

- There is no longer any unitary 'message system' to which people are routinely and consistently exposed, leading to stereotypes and the adoption of consensual values.

- Individuals can 'answer back' to figures of authority or remove themselves from contact. They can also participate actively in informational and opinion exchanges in the context of important social and political issues.

- In an 'always-on' online context there is a new kind of visibility of all actors in the mass communication process, offering opportunities while simultaneously raising concerns about democratization, participation, privacy and (in-)equalities.

These and similar propositions have become the basis for a staggering amount of research and new theory as we give shape to the 21st century. A careful balance needs to be maintained between hopeful accounts of the consequences of the newer media environment for alleviating human suffering (consider, for example, the role of smartphones and social media in the experiences of refugees and the rise of new social movements such as \#metoo and \#blacklivesmatter), remedying social inequalities (addressing recurring issues related to digital divides in society), and cultivating critical work regarding increasingly automated aspects of our media and mass communication environment (for example, regarding the built-in biases of algorithms and artificial intelligence systems). 


\section{CONTINUITY AND DISCONTINUITY}

Reviewing the historical trajectory of media and mass communication as a discipline this way, it seems that the basic tenets of the field hold, despite the fact that developments in technologies, industries, production processes as well as audience behaviours are both hybrid, complex and networked as much as they can be considered to be converging - seemingly upending timeworn concepts and categorizations in research and theory. What seems to be the meta-narrative of media and mass communication is embodied in the big shift from more or less stable structures to highly fluid and flexible structures across both our field and object of study. Examples of the seemingly stable media and mass communication structures that continue to inform much of the research and theorizing in our field, are:

- Media production taking place in newsrooms, on backlots and in offices of the corporate film and television system, within large holding firms and multinational corporations, on the workfloor of game studios and advertising agencies.

- Media content that is based on more or less consensual, industrially routinized and generally formulaic formats and genre conventions.

- Media audiences that are (or can be) massively aggregated and programmed around schedules and more or less predictable media events.

These three key elements of the mass communication process are increasingly fluid or 'liquid' today, in that their constituent elements change faster than it takes new structures to sediment (paraphrasing Bauman, 2000):

- A trend towards complex networked industry structures and value chains, with production increasingly organized through 'atypical' working arrangements that can stretch around the globe;

- The on-going development of a wide variety of multimedia, crossmedia and transmedia storytelling forms stretching across multiple media and platforms, increasingly including audiences in a more or less interactive role;

- Concurrent media exposure, co-creation and participation as newly standardized types of contemporary 'audiencing' (Fiske, 1992).

We can now see quite clearly that the era of mass communication is best viewed as a transitional phase of industrial mass public communication - while throughout the developments in the media there has been a continuity of mass communication as a society-wide process. This continuity today is established in new forms that are made up of a much finer and tightly woven network of lines and connections (online and offline) that has an organic character rather than 
being constructed and controlled by a few for their own ends. Although the structures that underpin the media and mass communication process are liquid, it is still possible to observe these various instances of production, content and reception, and to make generalizable statements about them. There is continuity in all this discontinuity.

Much of this constancy, however dispersed, hybridized, networked or automated, is observed in our field based on a relatively uniform set of fundamental assumptions, as outlined by Annie Lang (2013):

- First, media and mass communication are pervasive and ubiquitous.

- Secondly, media and mass communication act upon (and are acted upon by) people and their social environments.

- Thirdly, media and mass communication change both the environment and the person.

- Fourthly, the primary goals and questions of media and mass communication researchers are to demonstrate the various elements, roles, influences and effects of media and mass communication, and, if possible, explain how they come about.

These assumptions hold for both the humanities-inspired practice of media studies, and the social science-oriented domain of communication research, despite their sometimes different theoretical and methodological alignments. A sidenote here must be that we tend to make too much of the purported differences between the two paradigms (even seeing them as intrinsically 'competing'; see Lincoln \& Guba, 1994), especially in a contemporary context of increasingly interdisciplinary, mixed methods and integrative research.

\section{TOWARD A GRAND NARRATIVE}

The story of our field, as we can tell it to others, in all of this is twofold - and perhaps somewhat counterintuitive. On the one hand, it is clear from this overview that media are of profound importance. The two main scholarly traditions in our field align in their perspective that media and mass communication are (or can be) powerful agents of change in society, where communication research seeks to find evidence (and explanations) for such effects, and media studies tends to take this powerful role for granted, opting to explore avenues for critique of the way media operate in society (Lang, 2013). On the other hand, the end result of all this agreement and alignment must be that we have to conclude that, overall, media are not all that powerful. A century of scholarship leaves little doubt that media do have many effects and they probably do account for some general trends. However, media effects are inconsistent and often cancel each 
other out, and complex societies can be characterized by different lines of development and subsequent roles for media at the same time. As is the conclusion of much of the research in our field: media have some effects on some people in some circumstances some of the time.

This seemingly paradoxical narrative - media are everything, and they are nothing - is haunting our field. As the world is stuck behind a screen at home, public and political debates rage on cyberbullying and online harassment, the role of powerful algorithms and artificial intelligence, rising privacy and security concerns, problematic media use and media addiction, fake news and disinformation campaigns, conspiracy theories and declining trust in institutions. Our answer to all of this is consistently and necessarily ambiguous: yes, these are all important issues that clearly warrant our concern; no, none of these issues is likely to change much in how most people live their lives, make their decisions, nor in how society and its institutions generally function. If we 'decentre' the media for a moment, as Nick Couldry (2012) among others advocates, there are much broader, historical and contextualizing concerns behind these (and many other) pressing issues involving media and society: about 'good' parenting in a demanding and complex world, about human-machine relationships, about feeling whole and being recognized as such, about having a sense of belonging, and about taking responsibility in a globalizing context where the likelihood that you have something in common with someone who lives next-door seems less than finding cause of common concern with strangers online. In other words: media amplify and accelerate what already is there in the first place.

\section{WHAT TO DO WITH MEDIA AND MASS COMMUNICATION THEORY AND RESEARCH}

The combination of our field's fundamental assumptions and its altogether ambiguous narrative can make for a hard sell outside the walls of academia beyond the particulars of how media scholars work, publish, and get recognition in the institutional process of doing the work. An additional complicating factor is the signalled 'liquefaction' of the elements of the mass communication process, making stories about anything specific or particular to media production, content and reception necessarily complicated. Rather than fretting about what media and mass communication theory and research as a field is, I would suggest that a pertinent question becomes what can be done with it. Here I would like to put forward a few modest proposals regarding theory and research (including methods), and our professional identity as scholars in the world - proposals, based on interventions that have in common an aspiration to get academic teaching and research 'to work' for and with people, communities, and society. 


\section{POSITIONALITY}

To begin with, I would like to address the general trend (and recommendation) in the literature of our field in recent years pointing towards increasing integration and cross-fertilization of models, methods and paradigms in media and mass communication theory and research. It must be clear that this kind of integrative work is easier said than done. Academic units tend to be organized along either social scientific or humanistic disciplinary boundaries, scholarly journals are equally singular in their preferred approaches, and combining perspectives can be time-consuming and costly (for example, when it comes to multiple method research designs).

Beyond logistical and perhaps cultural complexities in making truly integrative research possible, it seems significant to take a step back to consider one's own position regarding doing such research in the first place. Who we are, how we feel about what we do, what keeps us up at night, what we really care about (when it comes to the role of media and mass communication in society and everyday life), and what we want to achieve needs to be made explicit, as it co-determines what we know and, more importantly, what we see when we look at our objects of study. As a first step, this means understanding how the kind of questions you ask tend to locate you in certain traditions, disciplinary siloes, and methodological conventions before you even get started with doing a literature review.

In an attempt to show how the most common approaches and themes in media and mass communication research align, Figure 1 proposes a rough guide. As an organizing principle I divided the field into research that focuses more or less explicitly on mass media and communication processes (such as the few-to-many production and diffusion of public information, including journalism, advertising, and propaganda), or work that looks specifically at personal media (which tends toward interpersonal processes of communication). It can be noted that the new media environment, shifting our time and attention towards portable and customizable always-on media, contributes to a collapsing of communication categories, while not necessarily negating them. A second organizing principle - represented on the model's horizontal axis - takes James Carey's (1975) distinction between a ritual and a transmission view of communication as its point of departure.

A transmission view considers communication as a process of transmitting a fixed quantity of information - the message as determined by the sender or source. This represents the linear sequence of sender $>$ message $>$ receiver which is largely built into standard definitions of the nature of predominant forms of mass communication. Although there are many ways in which this representation of the mass communication process can be challenged, it lives on because it usefully distinguishes the selecting role of specific mass communicators, it involves an appreciation that this selection is undertaken according 
to an assessment of what the audience will find interesting; and the third is that communication is not considered purposive beyond publication and seeking attention for its message. These assumptions about the process enable precise research questions and targeted theorizing about media effects and audience reception. The transmission model remains a useful representation of the rationale and general operation of some media in some of their functions (especially general news media and advertising) - if only because professional communicators and institutions tend to think primarily in such terms about the process of (mass) communication. It is, of course, incomplete and possibly misleading as a representation of most media activities and of the diversity of communication processes that are at work. One reason for its weakness is the limitation of communication to the matter of 'transmission'. Carey pointed to an alternative view of communication as 'ritual', according to which:

communication is linked to terms such as "sharing," "participation," "association," "fellowship," and "the possession of a common faith." This definition exploits the ancient identity and common roots of the terms "commonness," "communion," "community," and "communication." A ritual view of communication is directed not toward the extension of messages in space but toward the maintenance of society in time; not the act of imparting information but the representation of shared beliefs (1975: 18).

Seen as such, communication becomes an exchange - a participatory act where meanings depend on shared understandings and emotions, and where medium, message as much as sending and receiving of messages are hard to separate empirically.

Research in media and mass communication can be mapped along four key areas of investigation, each with its own prevailing perspectives about the nature of our relationship with (our) media. In quadrant 1 , studies that focus on how mass media messages influence and shape public opinion and sentiment can be grouped, generally consisting of media effects, agenda-setting and framing research. Studies in quadrant 2, while similarly interested in the workings of mass media, focus more on the historical and long-term mutual shaping of media, communication, culture and society. Approaches in this area were originally informed by media dependency theory (Ball-Rokeach and DeFleur, 1976), and more recently got rearticulated in terms of (deep) mediatization research in a conceptual attempt to move away from media effects while maintaining a mass media-centred focus (Hepp, Hjarvard and Lundby, 2015). 
Figure 1. An integrated model of media and mass communication research

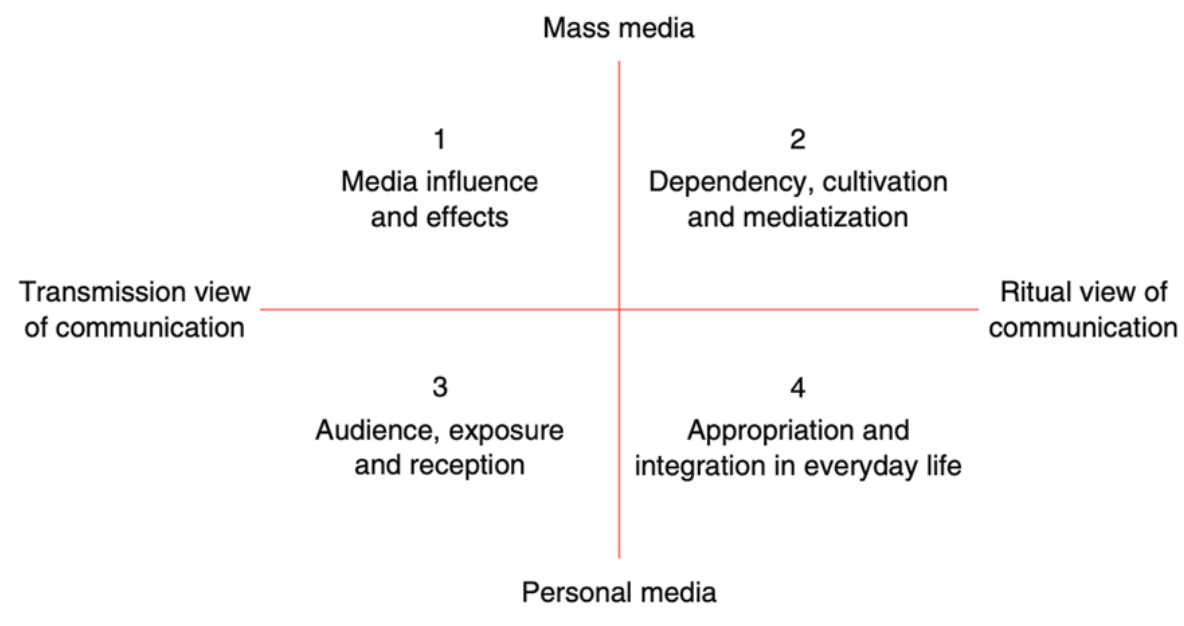

Source: McQuail \& Deuze (2020: 100)

Quandrant 3 turns our attention towards the various ways in which people use media, specifically when it comes to our personal and customizable media environment. Research in this area zooms in on people's motivations and uses of media (often informed by some version of uses and gratifications theory), encapsulating most audience and reception studies. Quadrant 4 extends this work by articulating the various media people use with the ways in which we organize and arrange our lives and lifestyles. Although such an approach to media as an ensemble of devices and activities collectively constituting how people understand, give meaning to and coordinate their everyday life has been advocated in the literature for many decades (Bausinger, 1984), only quite recently such work is becoming more common, giving rise to sophisticated theoretical and empirical work. What is missing from this model, is an elaboration of how research on media production fits in. Although production studies have been around since at least the 1950s (with early studies of film studios and newsrooms), since the early 2000s research and theory on media industries, production practices, work and management have blossomed into a fully fledged aspect of the discipline. Transmission-based work in production studies would be focused on the media making pipeline and across the entire product cycle of a media industry - including phases such as ideation, pitching and greenlighting, pre-production, production and post-production, packaging and promotion, distribution, and consumption. Scholars in this area of research are often inspired by a political economy approach to the media, which 'follows the money' in terms of its assumptions where media influence comes from at every phase of the production process. Ritual-based research on media production and work tends 
to be more interested in processes and meaning-giving practices of everyone involved in using and making media.

What I hope to accomplish with this model, is to assist researchers to see where their assumptions, chosen approaches and personal preferences position their work within the larger field of media and mass communication research. Although overlap exists and not every theory, project or research question neatly fits, it is important to consider that simply asking a certain question (about media and mass communication) in a way positions one at a specific point in this conversation that our field has with itself.

Positioning oneself in research is not just a matter of disciplinary alignment or fit with a particular epistemological tradition. The production of knowledge is not simply a matter of theory or method, it also involves a reflexive awareness of one's subjectivity as a researcher. In part, this 'positional reflexivity' (Macbeth, 2001) reminds us to be mindful of how our ideas, research questions and conventions, methodological choices and publishing choices are not simply our own, but all exist in a specific context: of one's disciplinary community and history, of power relations with peers, students, mentors and mentees, of one's position within the university and (or) beyond the Ivory Tower of academia. Yet, positional reflexivity demands more from us, as it "takes up the analysts' (uncertain) position and positioning in the world he or she studies and is often expressed with a vigilance for unseen, privileged, or, worse, exploitative relationships between analyst and the world" (ibid., 38). This means becoming aware of (and making explicit) how all the aspects that make up our social identity - including, but not limited to class, citizenship, ability, age and generation, race, sexual orientation, and cis/transgender - affect the way that we see and interpret the world around us, and how the world sees and interprets us. This perhaps sounds easier than it really is - not only are many aspects of our identity everchanging and dependent on context; it is often difficult to know which aspects of who we are become meaningful or influential in what particular stage of the research process. Furthermore, our identities are caught up in social structures - such as the family, one's research community and place of work, nationality and locality, so on and so forth. Danielle Jacobsen and Nida Mustafa (2019) for example offer a 'blank positionality map', through which exercise researchers are encouraged to translate the rather abstract and conceptual notion of positionality into tangible terms of practice. The combination of reflecting on one's scholarly as well as personal predisposition - and being able to tell that story - is an encouraging step toward taking more responsibility for what we do when we study, research or teach media and mass communication theory. 


\section{METHOD AS SELF-DEVELOPMENT}

Considering positionality in doing research leads me to a second point, one that was recently made so eloquently by Cristina Archetti in an essay on method development in media research: "method development could ultimately be understood as the practice of 'self-development' and, in the deepest sense, 'living life"' (2020: 2; italics in original). As she asks how we explain the complex, confusing, and crisis-ridden mediated reality as communication researchers, her answer comes back to choosing methods not on the basis of whether these are the 'right' or 'wrong' methods for a particular project, just as there are no 'right' or 'wrong' research questions to ask:

There are only methods that are more or less appropriate to the research questions we are pursuing, more or less consistent with the theories we use and with our own epistemological reflection. I also believe-you see, I am myself, just like any 'good method' should be, aligned with my theoretical framework-that the theories I use in my research also apply to making sense of myself, not just of my objects of study (ibid.).

Following Archetti's provocation, I would like to suggest that, ultimately, the questions we ask in our research are questions we ask of ourselves - and if this does not seem to be the case, we need to dig deeper as to why we want to know what we want to know, what frustrates us about not knowing, what is the mystery that waits to be demystified by us (Stevenson and Witschge, 2020)? Part of the answer to these questions locates our work within the larger field that we are part of, which should help us in articulating who we are, what it is we are doing, and what view (of the world and ourselves) informs this practice. As mentioned earlier, this in turn also would enable us to take responsibility for our work - not just within the university, but perhaps more importantly: to the people we study, the communities we are part of, the world we live in.

In this context, Sarah Tracy (2010) proposes that the quality of our research in part is determined by a combination of (a) worthy topic, (b) rich rigor, (c) sincerity, (d) credibility, (e) resonance, (f) significant contribution, (g) ethics, and (h) meaningful coherence. Working through these steps in the research process, one cannot escape the conclusion that much of the concepts require self-reflection, emotional openness and honesty on the part of the researcher. As Tracy remarks, being sincere in research requires "self-reflexivity about subjective values, biases, and inclinations of the researcher" (ibid., 840). Interestingly, Tracy was inspired to develop this conceptualization as a way to persuade nonacademic audiences and power holders that the research findings of scholarly inquiry deserve respect and are worth paying attention to. 


\section{METHODOLOGICAL ANARCHISM}

A subsequent move regarding theory and research is to further unpack the aforementioned claim made throughout the literature in media studies and communication research for more integrated theoretical frameworks, multiple methods and triangulation, in order to do justice to the complexities of our dynamic media environment and the mass communication process. Let me return to Waisbord's celebration of our field as a 'post-discipline' at the outset of this paper, and follow his argument specifically regarding the contemporary digital context:

We should recognize and embrace the proliferation of approaches to the study of digital communication amid the constant reinvention of fields of study related to 'communication studies'. This attitude demands challenging the modernist project of science identified with a single conceptual system and a finely defined and dominant paradigm, and defending ontological openness, not only in the name of intellectual originality but also as a distinctive quality of the continuous blurring of academic boundaries (2019: 90).

What Waisbord advocates is something emerging in various literatures, especially those that document what people do with (and in) social media, and what the consequences of our near-constant immersion in online networks and platforms could be (see for example Rogers \& Niederer, 2020; Griffioen et al., 2020). In these studies, three considerations come together: first, that in order for us to say anything meaningfully about what the consequences of (digital, social, always online) media are, we need to look at what people are actually doing with media. This is such a straightforward notion - yet one that is not always followed in research designs. Concerns about ecological validity (in the social sciences) and lived experience (in the humanities) abound as people are generally only asked about their media use, or their media use is documented in artificial settings. What is key here, is to gather data on what people do with digital media, for example based on the affordances of the digital (through data scraping, collecting log files, downloading personal account information, and so on).

A second consideration is, that media use and reflections on what media mean have to be seen in historical and material context: the same media experience last week (or yesterday) may mean something quite different today, in part influenced by what device, platform or technology someone is using, when and where they are using it, and in what particular context all of this takes place. Third, there is a growing realization across all areas in the field that objective data about people and their media as primarily expressed by our 'digital shadow' that we leave behind when using any kind of connected technology 
needs to be supplemented by people's 'emotional shadow' in order to understand what is happening. Or, as Tricia Wang (2013) has concisely stated: big data needs thick data:

Thick Data is data brought to light using qualitative, ethnographic research methods that uncover people's emotions, stories, and models of their world. It's the sticky stuff that's difficult to quantify. It comes to us in the form of a small sample size and in return we get an incredible depth of meanings and stories. Thick Data is the opposite of Big Data, which is quantitative data at a large scale that involves new technologies around capturing, storing, and analyzing (Wang, 2016).

This does not just concern research designs about media use, audiencing, or reception studies. Importantly, the inclusion of both objective data and insights from ethnographic approaches can also be found in media production research as well as content analyses (see in particular the special issue 'Speaking Across Communication Subfields' of the Journal of Communication of June 2020, edited by Keren Tenenboim-Weinblatt and Chul-joo Lee).

Another inspiring example is artography (Springgay \& Irwin, 2005) or artsbased research, which implements the arts - such as creative writing, poetry, theatre, song and dance - in one or more stages of the research process, and specifically asks of the artist/researcher/teacher $(\mathrm{A} / \mathrm{R} / \mathrm{T})$ to actively participate in the process of "doing and meaning making" with the community in which their research takes place (Leavy, 2009). Of course, there are countless examples across our field of scholars and students engaging in their communities, finding and creating concepts, methods, data and analyses with participants, and expressing their work in a variety of ways (for a specific application in journalism studies, see Hölsgens, De Wildt \& Witschge, 2020). Here, I just want to acknowledge the significance of this work in its potential to bring the story of our field to the public, while at the same time nestling our research more reflexively in the immerse, always-on and comprehensively mediated nature of people's everyday lives.

I want to add two nuances here. First, all of this is not just an argument for research designs employing mixed methods - where two or more distinct methods are combined in a single study. This should rather be taken as a recognition of hybrid methodologies, where the elements of different methods cannot be separated out. An example of this would be ethno-mining, where database mining and field research are merged, and where findings are both found and created in partnership - for example by asking study participants to reflect on the results of quantitative analyses by showing them data visualizations (Anderson et al., 2009). A second subtlety follows from this hermeneutic blending of methods, 
as this would require a genuine openness toward a proliferation of views, approaches, disciplinary perspectives, as well as methods in order to conduct this kind of research. Hitching ourselves behind a particular methodological wagon (or even two) is bound to lead to analytical pigeonholes. A tolerance for diversity in the ways in which we ask questions, gather data and make sense of our material necessitates coming to terms with our own vulnerabilities, anxieties, and overall feeling-state as researchers. Following Paul Feyerabend's original celebration of methodological anarchism, one way to make our work resonate with the communities beyond the university, is to recognize the multiple ways in which data makes sense to us, and to stay suspicious of the procedures and rules that guide us to particular conclusions in scientific research:

The history of science, after all, does not just consist of facts and conclusions drawn from facts. It also contains ideas, interpretations of facts, problems created by conflicting interpretations, mistakes, and so on. On closer analysis we even find that science knows no "bare facts" at all but that the 'facts' that enter our knowledge are already viewed in a certain way and are, therefore, essentially ideational. This being the case, the history of science will be as complex, chaotic, full of mistakes, and entertaining as are the minds of those who invented them (Feyerabend, 1975: 19).

With Feyerabend, I am not advocating against method per se, but rather suggest that we stay wary of using method as a way to dig a ditch between academic and nonacademic audiences. If we do follow our field's call for integrative research, then let it be truly integrative, allowing for the rationality of objective data as much as the serendipity of wonder and surprise (Witschge \& Deuze, 2020) to guide our work. I am reminded of Martin Heidegger, who remarked that observing and confronting the world puts one in a state of continuous awe and astonishment. Such a state of being in awe and astonishment, marveling and wonder is a way of holding oneself back while being enraptured by that from which it steps back. Heidegger asks us to "courageously take up the risk of holding ourselves open unto the Open" (cited in Capobianco, 2010, p. 85). In media studies, such an openness and marveling perspective can for example be found in the works of Paddy Scannell (2014) and John Durham Peters (2015).

\section{PUBLIC SCHOLARSHIP}

A final, fourth reflection here about what we could do with media and mass communication theory and research - beyond positionality (within the field, and in society), considering method as self-development, and making the case for openness and wonder - is to look at the various ways in which we can bring our scholarship into being. This is not just a matter of suggesting that we should 
not only publish in the kind of places that academic institutions privilege when making hiring, tenure and promotion decisions - such as ranked scholarly peer-reviewed journals and monographs published by prestigious university presses. There are countless scholars - graduate students, professors, and independent researchers alike - who actively blog, vlog, podcast, tweet, give interviews to journalists, publish open access white papers and research memos, and so on. To wit, I maintain a personal weblog ('Deuzeblog', since 2004), am reasonably active through my social media accounts (on Facebook since 2005, Twitter since 2008), now and then publish essays on the Medium platform, and during the pandemic of 2020 started a vlog (\#deuzevlog on YouTube) as well as a podcast (on Anchor.fm) where I interview media scholars that I am a fan of.

However, taking one's scholarly work beyond the university is more than just a matter of publication (and self-promotion). Here, Waisbord asks us all to embrace a notion of public scholarship, which is to consider "public engagement as an integral part of communication studies" (2019: 94). This for example means we should communicate and discuss scientific knowledge in and with various publics, and strive to do research with practical implications and learn from the public. As Adam Gaudry for example comments, just thinking about the people who participated in our research (as respondents or informants) when it is time to publish makes our work function as an 'extraction methodology', where "the context, values, and on-the-ground struggles of the people and communities that provide information and insight to the researcher" get lost (2011: 113). Gaudry recommends non-extractive or 'insurgent' research as an alternative approach, based on three core principles (which I am paraphrasing here):

(1) by explicitly employing nonacademic worldviews;

(2) by orienting knowledge creation toward nonacademic peoples and their communities (next to meeting research and publishing expectations of one's academic institution); and

(3) by seeing our responsibility as researchers as directed almost exclusively toward the community and participants.

Waisbord recognizes that this kind of work has history in our field. In fact, it could be argued that public scholarship represents one of two ways in which we engage with the public as scholars, the other one being an 'expert' model where the scholar indeed has (or tries to have) a seat at the table where policymakers and other stakeholders make decisions, orienting their work primarily at a highly educated academic audience or government bureaucracy.

Perhaps the expert versus engaged binary is too black and white, given recent trends across the academy to make research more relevant to the community in part indicated through external assessment protocols of universities, which increasingly emphasize impact and societal relevance as indicators of excellence. In a study by the 'Tenure Team Initiative' of Syracuse University in the 
US to recognize the work that faculty are doing in this area, Julie Ellison and Timothy Eatman locate publicly engaged academic work on a continuum, with traditional engagement and scholarship on one side, and "the most civically engaged or reciprocal scholarship and engagement" on the other (2008: ix). Amy Schalet, Linda Tropp, and Lisa Troy offer a third way beyond the either-or of expertise versus engagement, which they call a 'relational' model of public scholarship, urging "relationship building and mutual learning, as well as partnership during dissemination, while maintaining independence of thought, decision-making, and institutional affiliation during the processes of research design, data collection, and analysis" (2020: 1). At the heart of their suggested approach is finding, creating and (or) forging common ground between academics and nonacademic audiences. What is particularly interesting about their approach, as with the intervention of Gaudry, is the notion of public awareness or inclusion at all stages of the academic process - rather than just at the outcome. This mirrors earlier observations about positionality and hybridization: it is fascinating to think of reflexivity, inclusion, co-creation and collaboration across the entire circuit of knowledge production (through research and teaching), rather than just at the stage of knowledge dissemination.

It is important to include teaching here next to research, as a (engaged, insurgent or relational) scholar can think of knowledge production as well as dissemination beyond the journal article or monograph as much as beyond the formal classroom. More often than not, the engaged academic finds that her work needs to be made explicit - taking a stance about what should be done - in order to merit nonacademic appeal, which in turn necessitates critical self-reflection, self-development, and knowing where you stand. Within the classroom some reflexive awareness is called for too, especially given the on-going internationalization of the student population (Knight, 2011), and the continual rise in first-generation student enrollment (Wainwright \& Watts, 2019). As classes become more diversified, students' motivations, attitudes and activities also become more varied, with some students conforming to relatively static ideals of academic commitment, while many, if not most others coming to class primarily to obtain a qualification for a job. As John Biggs argues, there is a large a large gap between these types of students in terms of their level of engagement, and "good teaching should reduce the gap" (1999: 69; italics in original). His proposal is to follow a process of constructive alignment in our teaching, where teaching and learning activities, curriculum objectives, and assessment tasks are reflexively and explicitly aligned:

We have first to be clear about what we want students to learn, and then teach and assess accordingly in an aligned system of instruction (Biggs, 1999: 64). 
Note again in this proposal a clear choice for considering the entire academic process for open to intervention, rather than just one particular aspect or outcome. This is a pattern in the contemporary literature on public scholarship, academic engagement, and the role of critical self-reflection in the work we do at universities and other institutions of higher education: to look across the whole spectrum of activities and focus on the relations that 'tie the room together' (paraphrasing the character Jeffrey Lebowski in one of my favorite films: The Big Lebowski from the Coen brothers in 1998).

\section{CONCLUSIONS}

In this essay, I have tried to summarize some of the key challenges and opportunities in the field of media and mass communication theory and research, grounding my argument in the work of the late Denis McQuail - and that of editing the new edition of his seminal handbook McQuail's Media and Mass Communication Theory (McQuail \& Deuze, 2020). Given the contemporary context of a global pandemic alongside a worldwide infodemic, it makes sense for us to take stock of who we are as a field, and what our narrative is - how we can contribute to public debates about the role of media and (mass) communication in society and in everyday life.

By way of a historical appraisal of the fundamental traditions and approaches in our field, inspired by earlier work by Annie Lang (2013) and of course Denis McQuail, one could argue that all our work tends to be grounded by a relatively uniform set of fundamental assumptions: media and mass communication are pervasive and ubiquitous, must be seen and can best be understood in individual and social context, make a difference in both the environment and the person, and our primary role is to describe and, if possible, explain how the various elements, roles, contents, influences and effects of media and mass communication come about. Reviewing the main traditions of (humanities and social scientific) scholarship in our field, we have to conclude after a century of work that ubiquitous media are clearly of profound importance in society and everyday life, yet their direct influence and effects on human behavior are relatively modest. If anything, media amplify and accelerate what is already there - a key insight that inspires a growing number of scholars in the field to use and theorize media to look just beyond media in order to focus more closely on what people are actually doing with media. This 'decentering' of media in media and mass communication research can be considered to be an instance of what Slavoj Žižek (1992) passionately promotes as a way of 'looking awry' at our object of study: to never take what we study or find for granted, for always looking for different, and possibly disturbing explanations. 
After this review, I used this invitation to look awry at our field to look differently at ourselves in an attempt to provide some answers to the question, why the world - the nonacademic public - seemingly does not care about what we know (Kleis Nielsen, 2017), despite the fact that media and mass communication issues (such as online harassment, the role of algorithms and artificial intelligence, privacy and security concerns, problematic media use and media addiction, fake news and disinformation campaigns, et cetera) are top of mind around the world. In sequence, I considered how positionality, understanding the self as a research tool, implementing truly integrative study designs, and the emergence of engaged and public scholarship may provide four ways of rethinking our work in terms of what we can do with media and mass communication teaching and research.

All of this not to claim a necessarily 'new' intervention, and leaning heavily on inspiring and groundbreaking work by many, many others. Here I would like to explicitly acknowledge the work and praxis of Cristina Archetti, Tamara Witschge, and Silvio Waisbord as my main sources of inspiration, as well as the work of the late James Carey and, of course, Denis McQuail. I am furthermore deeply indebted to Deborah Castro and Johana Kotišová, who took the time to reflect and comment on an earlier version of this paper. None of us are in this alone.

A specific caveat to the positions taken in this essay must be that none of the themes of positionality, theoretical and methodological reflexivity, and public scholarship are particular to our field. Indeed, it can be said these are calls to action heard and relevant across all fields and domains in higher education and academic research. Perhaps their additional significance for work in media and (mass) communication lies in the everyday 'practicality' of our discipline (Craig, 2008), as ours is a 'productive science' that helps to makes sense of a world that people always already actively inhabit and make sense of (Jensen, 2019).

Taken together, it seems to me - as I also concluded at the end of our book, that "a rich vocabulary to talk about the implications of the developments of communication that are taking place is emerging - one that questions simplistic models and modes of doing research [...] What is also remarkable is that media and mass communication scholarship is finding all kinds of more or less new ways to communicate about itself [...] the future of media and mass communication theory and research holds much promise" (Deuze \& McQuail, 2020: 585). Adding the insights I gained from doing the research for this particular contribution, I can do little else but echo that conclusion.

\section{REFERENCES}

Anderson, K., Nafus, D., Rattenbury, T., \& Aipperspach, R. (2009). Numbers Have Qualities Too: Experiences with Ethno-Mining. EPIC 1: 123-140. 
Archetti, C. (2020). Research, methods, and the Zen art of questioning what you know. Norsk Mediatidsskrift 107(2): 1-7.

Ball-Rokeach, S.J., \& DeFleur, M.L. (1976). A dependency model of mass media effects, Communication Research, 3: 3-21.

Bauman, Z. (2000). Liquid Modernity. Cambridge: Polity.

Bausinger, H. (1984). Media, technology and daily life. Media, Culture \& Society, 6: 343-351.

Biggs, J. (1999). What the Student Does: teaching for enhanced learning. Higher Education Research \& Development 18(1): 57-75.

Capobianco, R. (2010). Engaging Heidegger. Toronto: University of Toronto Press.

Carey, J.W. (1975). A cultural approach to communication, Communication (2): 1-22.

Castells, M. (2009). Communication Power. Oxford: Oxford University Press.

Chadwick, A. (2017). The Hybrid Media System. Oxford: OUP.

Couldry, N. (2012). Media, Society, World: Social Theory and Digital Media Practice. Cambridge, UK: Polity.

Craig, R.T. (2008). For a Practical Discipline. Journal of Communication 68: 289-297.

Deuze, M. (2020). The Role of Media and Mass Communication Theory in the Global Pandemic. Communication Today 11(2): 4-16.

Deuze, M. (2021). On the 'Grand Narrative' of Media and Mass Communication Theory and Research: A Review. Profesional de la Información 30(1). DOI: 10.3145/epi.2021.ene.05.

Durham Peters, J. (2015). The Marvellous Clouds. Chicago: University of Chicago Press.

Ellison, J., \& Eatman, T. K. (2008). Scholarship in Public: Knowledge Creation and Tenure Policy in the Engaged University. Imagining America 16. Retrieved November 30, 2020 from: https://surface.syr.edu/ia/16.

Feyerabend, P. (1975). Against Method: Outline of an Anarchistic Theory of Knowledge. London: Verso.

Fiske, J. (1992). The cultural economy of fandom. In: L. Lewis (ed.), The Adoring Audience, 30-49. London: Routledge.

Fuchs, C. (2020) Everyday Life and Everyday Communication in Coronavirus Capitalism. tripleC 18(1): 375-399.

Gaudry, A.J.P. (2011). Insurgent Research. Wicazo Sa Review 26(1): 113-136.

Griffioen, N., Rooij, M.M.J.W. van, Lichtwarck-Aschoff, A., \& Granic, I. (2020). Toward improved methods in social media research. Theory, Mind and Behavior 1(1): 1-15.

Guba, E. G., \& Lincoln, Y. S. (1994). Competing paradigms in qualitative research. In: N. K. Denzin \& Y. S. Lincoln (Eds.), Handbook of qualitative research (p. 105-117). London: Sage.

Hepp A., Hjarvard S., \& Lundby K. (2015). Mediatization: Theorizing the interplay between media, culture and society. Media, Culture \& Society 37(2): 314-324.

Hölsgens, S., de Wildt, S. \& Witschge, T. (2020). Towards an Experientialist Understanding of Journalism: Exploring Arts-based Research for Journalism Studies, Journalism Studies, 21:7: 928-946.

Jacobson D., \& Mustafa N. (2019). Social Identity Map: A Reflexivity Tool for Practicing Explicit Positionality in Critical Qualitative Research. International Journal of Qualitative Methods 18: 1-12.

Jensen, K.B. (2019). The Double Hermeneutics of Audience Research, Television erNew Media, 20(2): 142-154.

Knight, J. (2011) Five Myths about Internationalization. International Higher Education 62, DOI: 10.6017/ihe.2011.62.8532 . 
Lang, A. (2013). Discipline in Crisis? The Shifting Paradigm of Mass Communication Research, Communication Theory 23: 10-24.

Leavy, P. (2009). Method meets art: Arts-based research practice. New York: Guilford.

Lewis, S. C. (2020). What is Communication Research for? Wrestling with the Relevance of What We Do. In: M. Powers \& A. Russell (eds.), Rethinking Media Research for Changing Societies, Cambridge: Cambridge University Press.

Livingstone, S. (2009). On the mediation of everything, Journal of Communication, 59(1): 1-18.

Macbeth, D. (2001). On "Reflexivity" in Qualitative Research: Two Readings, and a Third. Qualitative Inquiry 7(1): 35-68.

McQuail, D., \& Deuze, M. (2020). McQuail's Media and Mass Communication Theory. London: Sage.

Nielsen, R.K. (2018a). No One Cares What We Know: Three Responses to the Irrelevance of Political Communication Research. Political Communication, 35:1: 145-149.

Nielsen, R.K. (2018b). If journalism studies research want to be part of the conversation about the future of journalism, we need to start showing up. Rasmuskleisnielsen.net May 26, Retrieved November 30, 2020 from: https://rasmuskleisnielsen.net/2018/05/26/if-journalism-studies-research-wantto-be-part-of-the-conversation-about-the-future-of-journalism-we-need-to-start-showing-up/.

Rogers, R., \& Niederer, S. (2020). The Politics of Social Media Manipulation. Amsterdam: AUP.

Scannell, P. (2014). Television and the meaning of 'live'. Cambridge: Polity.

Schalet, A.T., Tropp, L., \& Troy, L.M. (2020). Making Research Usable Beyond Academic Circles: A Relational Model of Public Engagement. Analyses of Social Issues and Public Policy, 1-21. DOI: 10.1111/asap.12204.

Springgay, S., \& Irwin, R.L. (2005). A/r/tography as Living Inquiry Through Art and Tekst. Qualitative Inquiry 11(6): 897-912.

Stevenson, M., \& Witschge, T. (2020). Methods we live by: Proceduralism, process, and pedagogy. NECSUS_European Journal of Media Studies 9(2), 117- 138. DOI: 10.25969/mediarep/15344.

Tenenboim-Weinblatt, K., \& Lee, C. (2020) Speaking Across Communication Subfields. Journal of Communication 70(3): 303-309.

Tracy, S. (2010). Qualitative Quality: Eight “Big-Tent” Criteria for Excellent Qualitative Research. Qualitative Inquiry 16(10): 837-851.

Wainwright, E., \& Watts, M. (2019). Social mobility in the slipstream: first generation students' narratives of university participation and family. Educational Review, DOI: 10.1080/00131911.2019.1566209.

Waisbord, S. (2019). The Communication Manifesto. Cambridge: Polity Press.

Wang, T. (2013). Big Data Needs Thick Data. Ethnography Matters, May 13. Retrieved November 30, 2020 from: http://ethnographymatters.net/blog/2013/05/13/big-data-needs-thick-data/.

Wang, T. (2016) Why Big Data Needs Thick Data. Medium, January 16. Retrieved November 30, 2020 from: https://medium.com/ethnography-matters/why-big-data-needs-thick-data-b4b3e75e3d7.

Witschge, T., \& Deuze, M. (2020). From Suspicion to Wonder in Journalism and Communication Research. Journalism \& Mass Communication Quarterly 97(2): 360-375.

Žižek, S. (1992). Looking Awry: An Introduction to Jacques Lacan through Popular Culture. Boston: MIT Press. 